\title{
Can Psychological Interventions Improve Intergroup Attitudes Post Terror Attacks?
} [ACCEPTD IN SOCIAL PSYCHOLOGICAL AND PERSONALITY SCIENCE]

\author{
Jasper Van Assche ${ }^{1}$, Masi Noor ${ }^{2}$, \\ Kim Dierckx ${ }^{1}$, Muniba Saleem ${ }^{3}$, Pierre Bouchat ${ }^{4}$, Laura de Guissme ${ }^{4}$, Dries Bostyn ${ }^{1}$, \\ Mark Carew ${ }^{5}$, Andreea Ernst-Vintila ${ }^{6}$, \& Melody M. Chao ${ }^{7}$ \\ ${ }^{1}$ Department of Developmental, Personality and Social Psychology, Ghent University \\ ${ }^{2}$ School of Psychology, Keele University \\ ${ }^{3}$ Department of Communication Studies and Institute of Social Research, \\ University of Michigan \\ ${ }^{4}$ Center for Social and Cultural Psychology, Université Libre de Bruxelles \\ ${ }^{5}$ Leonard Cheshire Disability and Inclusive Development Centre, \\ University College London \\ ${ }^{6}$ Laboratoire Parisien de Psychologie Sociale, Université Paris Ouest Nanterre La Défense \\ ${ }^{7}$ Department of Management, Hong Kong University of Science and Technology
}

This research was partially supported by a postdoctoral research grant from the Research Foundation - Flanders (FWO) awarded to Jasper Van Assche (FWO.3E0.2018.0049.01) under supervision of Arne Roets, through grants awarded to Melody M. Chao by General Research Fund (Ref No. 16601817) of the Research Grant Council of Hong Kong SAR government, Masi Noor by British Academy (SQ120061), and Melody M. Chao and Masi Noor by Keele University's Institute of Liberal Arts and Sciences. Please direct correspondence to either Jasper Van Assche, Ghent University, Faculty of Psychology and Educational Sciences, Henri Dunantlaan 2, B-9000 Ghent, Belgium, Jasper.VanAssche@UGent.be or Masi Noor, Keele University, School of Psychology, Staffordshire, ST5 5BG, m.noor@keele.ac.uk 
Word count: 4,998

Running head: Improving Attitudes Post Terror 


\begin{abstract}
This research concurrently investigated the effectiveness of three established biasreducing interventions (i.e., positive affirmation, secure attachment, and cognitive dissonance) in the wake of the Paris and Brussels terror attacks. Using frequentist and Bayesian analyses, Study $1(N=1676)$, launched within days of the attacks, found that compared to a control condition, the interventions did not significantly improve intergroup attitudes. Instead, the data showed strong support of the null hypotheses that there were no intervention effects. Proximity to the attacks did not moderate the effect. Study $2(N=285)$ re-examined the effects of the three interventions 2.5 years after the attacks, generally replicating the pattern of findings in Study 1. Together, this research highlights the challenge of intergroup biasreduction following terror attacks. We conclude by discussing several recommendations for how psychological interventions could play a more impactful role in contexts of heightened conflict.
\end{abstract}

Key words: terrorism; intergroup attitudes, self-affirmation; secure attachment; dissonance induction 


\section{Can Psychological Interventions Improve Intergroup Attitudes Post Terror Attacks?}

Aside from destroying lives, terror attacks disrupt community cohesion and intergroup relations (Kaiser, Vick, \& Major, 2004; Van De Vyver, Houston, Abrams, \& Vasiljevic, 2016), by sowing the seeds of hostility and suspicion (Kruglanski \& Fishman, 2009). Terror attacks can also increase unfavorable attitudes towards groups that share common social attributes with the terrorists (e.g., being Muslim; Doosje, Branscombe, Spears, \& Manstead, 1998). To illustrate, following the Madrid attacks in 2004, average levels of stereotypes towards related (Arabs) and even unrelated (Jews) outgroups increased (Echebarria-Echabe \& Fernàndez-Guede, 2006), akin to the U.S. public opinion data showing elevated national levels of racism and Islamophobia among Americans after the 9/11 attacks (Panagopoulos, 2006). Moreover, terror attacks can also instill individuals with the motivation for vicarious retribution (Lickel, Miller, Stenstrom, Denson, \& Schmader, 2006), prompting violent counter-attacks against the "guilty by association" (e.g., a White man driving a van into a group of Muslims near a north London mosque; The Guardian, 2017; Doosje et al., 1998; Pratt, 2015). Such attempts to take justice into one's own hand may ironically advance the very objective of terrorism to corrode individuals' confidence in their government's ability to protect its citizens. In fact, blame may be attributed to one's own government for provoking such attacks (Kruglanski \& Fishman, 2009), resulting in further social and political divide in the societies.

To mitigate these damaging consequences of terrorism, psychological interventions could be helpful. Past studies have shown that several interventions are effective in reducing intergroup biases, such as self-affirmation (Čehajić-Clancy, Effron, Halperin, Liberman, \& Ross, 2011), secure attachment (Saleem et al., 2015), and cognitive dissonance (Exline, Baumeister, Zell, Kraft, \& Witvliet, 2008). However, they are often examined in isolation. Little is known about their comparative effectiveness. Even less is known about whether these 
bias reduction interventions would be effective in a post-terror attack environment when social stigmas and biases run high. The present research addresses these issues. Specifically, we concurrently examined the effectiveness of three established interventions in the wake of the 2015 and 2016 ISIS terror attacks in Paris and Brussels. The effects of these interventions were examined on a wide range of intergroup outcomes among participants who were in close (the French and Belgians) or distant (the British and Americans) proximity to these terrorist attacks, being affected either directly or vicariously, respectively.

\section{The Current Research}

This research focused on three established bias-reduction interventions-selfaffirmation, secure attachment, and cognitive dissonance-for a number of reasons. First, all three interventions are premised on a similar basic principle in that their effectiveness relies on focusing on aspects of the self (e.g., being reminded of a positive self, the self being attached to a significant figure, or being reminded of a wrongful collective that the self was part of) to shift intergroup attitudes. Second, these interventions are typically implemented by engaging participants with the manipulation through writing prompts, thereby reducing potential methodological confounds. Third, these interventions have all established their effectiveness in bias reduction (e.g., Adams, Tormala, \& O’Brien, 2006; Exline et al., 2008; McGregor, Haji, \& Kang, 2008; Saleem et al., 2015; Stone, Whitehead, Schmader, \& Focella, 2011). Fourth, comparing the relative effectiveness of these interventions has important novel contributions. Specifically, these interventions are the products of co-evolved theories that have been developed independent of each other. Their effectiveness has been tested separately, leading to disparate strands of literature. The current research offers a crucial departure from past research by examining the comparative effectiveness of these interventions concurrently. Fifth, traditionally, research associated with the three interventions is often conducted in laboratory contexts employing minimal group paradigm 
with little history of intergroup tension, hostility, and terror (but see Čehajić-Clancy et al., 2011 for an exception). Therefore, the present research further advances the literature by testing the intervention effectiveness squarely in a real-life setting at a time of heightened societal tension.

It is important to note that the conditions under which the three interventions were examined here (i.e., in the aftermath of major terror attacks) were substantively different from those in past research (i.e., laboratory-based and minimum group paradigm-based studies involving artificially created groups with no history of enmity; Hebl \& Dovidio, 2005). Consequently, the present research is not a direct replication of past research (Shrout \& Rodgers, 2018). Rather, while maintaining identical manipulations as in past research, our work should be conceived as a conceptual replication with the aim to assess the relative intervention effectiveness and its generalizability across real-life settings (Fabrigar \& Wegener, 2016). Reducing the current work to simply a replication or reproducibility study would be to lose sight of the novel contributions (see the five contributions mentioned above) this research offers. Crucially, by examining the relative effectiveness of the interventions, this study is primarily addressing the practical question of what can be done to improve intergroup attitudes following terror attacks. As such, this study also responds to recent calls to assess the societal relevance of laboratory-based interventions by examining them in more ecologically valid contexts (Giner-Sorolla, 2019; Paluck \& Green, 2009). Below, we outline the gist of the theoretical underpinnings behind each selected intervention.

Self-affirmation. According to Self-Affirmation Theory (Sherman \& Cohen, 2006), individuals can tolerate threats to a specific aspect of their identity, so long as they can shift their attention to another aspect of their identity that is valued but not related to the one being threatened. For instance, induction of self-affirmation (but not group-affirmation) has been reported to increase willingness to accept responsibility for ingroup harm, feelings of 
collective guilt, and endorsement of reparation policies (Čehajić-Clancy et al., 2011). Selfaffirmation is also known to reduce various types of prejudice, including religious stereotyping (Fein \& Spencer, 1997) and sexual prejudice (Lehmiller, Law, \& Tormala, 2010).

Secure attachment. Attachment theory highlights the psychological importance of the connection one has with (significant) others. Crucially, it theorizes that in response to threat and fear, individuals tend to seek proximity to attachment figures, whose supportiveness can lessen fear reactions (Bowlby, 1969, Saleem et al., 2015). In intergroup contexts, priming secure attachment reduces negative intergroup emotions and stereotypes as well as increases people's prosocial attitudes and behaviors (Gillath, Sesko, Shaver, \& Chun, 2010; Mikulincer \& Shaver, 2001; Mikulincer, Shaver, Gillath, Nitzberg, 2005). Of importance to the present research, secure attachment can reduce negativity in intergroup interactions (Saleem et al., 2015).

Cognitive dissonance. Cognitive dissonance is induced through reminders of one's inconsistent beliefs and actions (Festinger, 1962). Holding two incompatible attitudes is known to induce dissonance. To resolve such dissonance, attitudes are often changed, and this can be pursued as an effective strategy (Festinger, 1962). This intervention can involve the notion of the "myth of pure evil", which refers to the belief that those who commit serious transgressions are bad people that are fundamentally different from good people such as oneself and one's ingroup members (Baumeister, 1997). Studies have shown that inviting victims to reflect on their own groups' capability to inflict similar harm onto others can increase victims' empathy and even forgiveness towards their perpetrator groups (e.g., Exline et al., 2008). That is, in the present research, reminding individuals of their own potential fallibility might also reduce intergroup hostility following terror attacks. 
Drawing on this intervention literature, we predicted that compared to the control condition, the three interventions would improve outgroup attitudes. Indeed, each of them might work for different reasons, given they operate along different psychological mechanisms. In particular, self-affirmation could restore participants' threatened self-esteem after a terror attack aimed at their entire ingroup. In a similar vein, after terror attacks, people often seek support from one another, and therefore secure attachment could make this support from significant others mentally available. Finally, dissonance may help victimized individuals to cognitively rationalize the terror events by framing and "explaining" them as retaliatory attacks provoked by their own government's foreign policies (e.g., invasions into Afghanistan and Iraq). Hence, we expected all three interventions to work, but we did not have a priori predictions about which interventions would be more effective relative to the others.

\section{Study 1}

On November 13, 2015 and March 22, 2016, the Islamic State of Iraq and Syria (ISIS) carried out several attacks in the hearts of the capitals of France and Belgium, respectively. These attacks killed 164 people and left more than 620 citizens injured. To examine the biasreduction intervention effectiveness, data collection commenced within days following the attacks and was completed approximately three months after the attacks. Because it is plausible that proximity to the attacks may moderate the impact of the terrorist attacks and thereby may interact with the intervention strategies, our sample included both participants who were directly affected by the attacks (Belgians and French) as well as those who were geographically remote from the attacks, but whose countries' governments have pursued foreign policies that could be seen as provoking such terror attacks (British and Americans).

\section{Method}

\section{Participants}


Our original sample comprised 1844 adults. Data were collected via university fora, Crowd-flower, M-Turk, and social media snowballing within days following the Paris and Brussels attacks $(M=9.05$ days after the attack; $S D=7.97 ; 90 \%$ of participants responded within two weeks). All measures were administered in the official main language of the country where data were being collected (i.e., English in the U.S. and U.K., French in France and the Belgian sample). To obtain reliable translations, two co-authors, who are academic psychologists fluent in English and French, independently translated the original version and back-translated the other's translation. Afterwards, all authors compared both versions to inspect their equivalence in order to arrive at consensual agreement on the final wording (for a similar procedure, see e.g., Chen, Van Assche, Vansteenkiste, Soenens, \& Beyers, 2015).

Only those participants who had provided meaningful responses (i.e., in relation to the intended manipulation prompts) were included. As such, 71 (29 American, 11 British, 24 French, and 7 Belgian) respondents were omitted because their priming responses indicated that they had not followed the specific manipulation instruction. That is, some respondents left the answering box open $(N=23)$, merely copy-pasted the instruction $(N=1)$, gave a very short, uninformative response (e.g., "good experience", "friends", “cool”, "felt proud", or "loss of confidence"), or stated that they had "no idea" $(N=16)$, "don't remember any experience" $(N=14)$, "don't understand the question" $(N=4)$, or that they did not want to share personal details $(N=1)$. Finally, eleven participants were excluded because they gave nonsensical responses, such as "feef", "X", or "good light". Further, 44 respondents were omitted from the analyses because they failed to correctly respond to the attention check question (see supplemental online materials, SOM, for more information). Finally, 26 (1 American, 3 British, 12 French, and 10 Belgian) and 27 (15 British, 7 French, and 5 Belgian) were excluded because they had an Arab (or mixed Arab) background and their religious 
affiliation was Islam, respectively. These participants were excluded because it was unclear whether their responses represented intergroup or intragroup attitudes.

The final sample for the present analysis came from 1676 White Caucasian online respondents $(37 \%$ male; $M$ age $=30$ years; $S D=12.37 ; 381$ French, 169 Belgians, 688 British, and 438 Americans). Politically, the sample was normally distributed in terms of left to right spectrum (31\% left, $44 \%$ center, $25 \%$ right). This sample also ensured, at least, 350 participants per condition, which is double the number of participants per condition used in past research. A power analysis (using $\mathrm{G}^{*}$ Power) revealed that our statistical power to adequately detect both a small and a medium main effect in this sample was well above the recommended standard of .80 (power $\geq .99$ ). Nonetheless, the sample may be underpowered to detect interaction effects between intervention and country.

\section{Procedure}

In both studies, we report all measures, manipulations and exclusions. Our study included an Intervention (self-affirmation, secure attachment, dissonance, \& control) X Country (France, Belgium, USA \& UK) between-participants design.

Interventions. The instructions for the manipulations were taken verbatim from published work:

- self-affirmation, identical to Čehajić-Clancy et al. (2011, Study 2, p. 261): “Think about your greatest personal strength of which you are really proud. Recall a time when you used this personal strength to achieve a personal goal. Please briefly describe what this experience was like.",

- secure attachment, identical to Saleem et al. (2015, Study 3, Online Appendix, p. 26): "Recall a time when someone close to you was available, supportive, and loving. This could be a family member, relationship partner, or close friend. Please briefly describe what this experience was like below.", 
- cognitive dissonance (reminder of ingroup potential for harm-doing) modelled on Exline et al. (2008, Study 4, p. 504): "Recall a time when your country unjustly harmed another nation. Please briefly describe the impact of this event on the harmed nation below.", and

- control, identical to Saleem et al. (2015, Study 3, Online Appendix, p. 26): "Recall an uneventful, normal day in your week. Please briefly describe what your routine activities are during such a day".

\section{Measures}

All measures were answered on a Likert scale anchored by 0 (not at all) and 100 (very much). Full measures are available in the SOM.

Pre-experimental measures. As recommended in the attachment literature (e.g., Mikulincer \& Shaver, 2001), trait anxiety and avoidance were measured prior to the manipulation and controlled for when analyzing the effects of secure attachment primes. Additionally, gender, age, ingroup identification, and political orientation were measured prior to the experimental materials and were controlled in the analyses similar to practices reported by past research (Čehajić-Clancy et al., 2011; Saleem et al., 2015).

\section{Post-experimental measure.}

Mood. To isolate the potential effects of mood from the experimental manipulations, we included a mood measure (Mikulincer \& Shaver, 2001).

Intergroup attitudes. Ten measures, borrowed from past literature, tapped different dimensions of intergroup attitudes: 1a) negative emotions towards terrorists, 1b) towards nonISIS Muslims, and 1c) towards the ingroup government; 2) dehumanization of terrorists; 3) competitive victimhood orientation towards Muslim victims; 4a) assigning responsibility for the attacks to one's government, and 4b) to non-ISIS Muslims, 5) reconciliation towards nonISIS Muslims, 6) future forgiveness of ISIS, and 7) punitiveness towards ISIS (degrees of 
torture). We assessed this wide range of intergroup attitudes for a number of reasons. First, we wanted to ensure that our study included the key outcome measures used in the disparate literatures that have emerged from the different interventions (see self-affirmation research for using acceptance of ingroup responsibility, Čehajić-Clancy et al., 2011; see secure attachment research for using intergroup negative emotions, Saleem et al., 2015; see dissonance research for using a forgiveness measure, Exline et al., 2008). Second, we also wanted to include measures aimed to capture the latest state of the art in intergroup literature (e.g., blatant dehumanization; Kteily, Bruneau, Waytz, \& Cotterill, 2015; competitive victimhood; Shnabel, Halabi, \& Noor, 2013). Finally, this wide range of dependent variables also ensured a broad scope for the interventions to exert their effects.

\section{Results}

\section{Frequentist Analyses}

A one-way ANOVA was conducted and revealed no experimental effect on participants' $\operatorname{mood}\left(F=1.83, p=.139 ; \eta^{2}=.003\right)$. Therefore, we can rule out any interferences of mood with our key outcomes (Carnelley \& Rowe, 2010). Next, we examined the effect of the experimental manipulation on the main dependent variables. Given the large number of tests, we applied the Bonferroni correction method when conducting multiple comparisons (i.e., $p$-values were multiplied by factor 6). After controlling for trait avoidance and anxiety, age, gender, ingroup identification, and political orientation (as recommended by Mikulincer \& Shaver, 2001), results revealed that, compared to the control condition, the interventions failed to exert a significant effect on the dependent variables (all $F \mathrm{~s}<1.90$, all $p s>.13$; all $\left.\eta^{2} \mathrm{~s}<.004\right)$. This pattern of findings also held up without the inclusion of the control variables (all $F_{\mathrm{s}}<1.81$, all $p \mathrm{~s}>.14$; all $\eta^{2} \mathrm{~s}<.003$ ). Moreover, no significant interaction effects were observed between the intervention manipulations and country (all $F \mathrm{~s}$ $<1.07$, all $p \mathrm{~s}>.38$; all $\eta^{2} \mathrm{~s}<.006$ ), meaning none of the interventions was more effective than 
the control condition, regardless of participants' proximity to the attacks (i.e., country). Of less relevance to the current study, country as a factor yielded a significant main effect. Overall, participants further away from the attacks appeared to display more outgroup bias than those living in the affected countries. These effects, including those of the intervention factor, are reported in full detail in the supplemental materials.

The observed results unexpectedly provided no evidence in support of our main hypothesis. Given the large sample, these results are not due to insufficient power. In fact, to our knowledge, the current sample is by far the largest recorded sample in the literature. Still, frequentist analysis cannot offer a formal approach to directly evaluate the null hypothesis model (Gallistel, 2009; Shrout \& Rodgers, 2018, p. 496). In order to gain further confidence in the present results, Bayesian analyses were conducted to directly test whether the given data would support the null hypothesis.

\section{Bayesian Analyses}

Using the BayesFactor package in $\mathrm{R}$ (with default priors Cauchy $=1$ by Morey $\&$ Rouder, 2015), we calculated Bayes factors for the main effect for our experimental manipulations, the main effect for country, and their interaction on all ten outcomes (see Table 1). Bayes factors quantify the support for a specified alternative model versus a null model (or vice versa). A Bayes factor of 5 suggests that the alternative model is about 5 times more likely than the null model, whereas a Bayes Factor of 0.2 suggests the opposite. Crucially, in the present study, all indices of the manipulation effect yielded very strong $(<$ $0.033)$ to even extreme $(<0.01)$ support in favor of the null model. For example, the Bayes factors for the experimental manipulation having an impact on emotions towards terrorists, Muslims, and one's own government suggest that, respectively, it is about 222, 661, and 78 times more likely that the manipulation did not have an impact than that it did (Table 1). 
Similar to the frequentist analyses, results from Bayesian analyses converge and show that there are neither manipulation nor manipulation X country effects. Finally, support for the country main effect was substantial, as evidenced by the large Bayes factors (see Table 1). Similar to the frequentist analyses, respondents in remote countries (i.e., U.S. and UK) tended to be more biased toward the various outgroups than those in affected countries (i.e., France and Belgium). This proximity effect echoes Prasad's (1935) work showing that reports of calamitous events spread rapidly and, through feelings of uncertainty and fear, might yield an even bigger impact on the unaffected (see also Festinger et al., 1948; Pezzo \& Beckstead, 2006). Nevertheless, other differences between these countries (e.g., in terms of religious or political systems) might also account for this effect.

\section{Table 1.}

Bayes factors for the manipulation, country, and manipulation*country effect on each outcome in Study 1, comparing the probability of the $H^{a}$ model (i.e., "there is an effect") being true as opposed to the $H^{0}$ model (i.e., "there is no effect") being true. Smaller Bayes factors indicate that the data is in support of the Ho model.

\begin{tabular}{lccc}
\hline Dependent Variable & Manipulation & Country & Manipulation*Country \\
\hline Negative emotions towards terrorists & 0.005 & 49.280 & 0.000 \\
Negative emotions towards Muslims & 0.002 & 193.401 & 0.001 \\
Negative emotions towards own government & 0.013 & 9411.171 & 0.000 \\
Dehumanization of terrorists & 0.008 & 1003.462 & 0.001 \\
Competitive victimhood & 0.020 & 0.375 & 0.001 \\
Ingroup government responsibility & 0.008 & 3.954 & 0.001 \\
Outgroup (non-ISIS Muslim) responsibility & 0.004 & 92.029 & 0.000 \\
Reconciliation towards non-ISIS Muslims & 0.007 & 522.381 & 0.001 \\
Future forgiveness of ISIS & 0.012 & 1.208 & 0.000 \\
Punitiveness (torture justification) & 0.002 & 436.005 & 0.009 \\
\hline
\end{tabular}


The results of Study 1 indicated that the interventions did not improve intergroup attitudes following the terror attacks. Past research has shown that following traumatic events, humans are likely to generate "freeze" responses (Schauer \& Elbert, 2010; Schmidt, Richey, Zvolensky, \& Maner, 2008). It is possible that the interventions were ineffective due to freezing immediately after the attacks. To examine this possibility, Study 2 tested the same interventions 2.5 years after the original attacks. Moreover, although research has demonstrated that the quality of data obtained from online platforms are no different from the quality of data obtained offline (Buhrmester, Kwang, \& Goslin, 2011; Goodman, Cryder, \& Cheema, 2013), to rule out that the results of Study 1 were not due to the online mode of data collection, data in Study 2 were collected from university students in a laboratory setting.

\section{Method}

\section{Participants}

Two hundred and ninety-six Belgian students were invited to the lab in small groups, and they participated in the online study in return for partial course credit. All measures were administered in Flemish, after careful back-translation by two bilingual coauthors (cf., Study 1). All participants provided meaningful responses (i.e., in relation to the intended manipulation prompts) and correctly responded to the attention check question (see supplemental materials for more information). Eleven respondents were excluded because they had an Arab (or mixed Arab) background. As in Study 1, these participants were excluded because it was unclear whether their responses represented intergroup or intragroup attitudes. Politically, the sample leaned toward a centrist and leftist orientation (40\% centrist, $45 \%$ leftist, and $15 \%$ rightist; generally reflecting the trends in the latest national elections, see Van Assche, Van Hiel, Dhont, \& Roets, 2019). The final sample comprised of 285 White Caucasian students ( $20 \%$ male; $M$ age $=19$ years; $S D=5.09$ ), with at least 70 participants per 
condition. A power analysis revealed that our statistical power in this sample was .81 to detect a small effect, and .95 to detect a medium effect.

\section{Procedure and Measures}

Study 2 included a between-participants design with participants randomly assigned to one of the four conditions (self-affirmation, secure attachment, dissonance, vs. control). The materials were identical to those used in Study 1. All measures were answered on a Likert scale anchored by 0 (not at all) and 7 (very much). For full instructions, see supplemental materials.

\section{Results}

\section{Frequentist Analyses}

Similar to Study 1, a one-way ANOVA revealed no experimental effect on participants' $\operatorname{mood}\left(F=0.13, p>.250 ; \eta^{2}=.001\right)$. Therefore, we can rule out any interferences of mood with our key outcomes. Next, we examined the effect of the experimental manipulation on the main dependent variables, applying the Bonferroni method to correct for multiple comparisons. As in Study 1, we report the main results with (as recommended by Mikulincer \& Shaver, 2001) and without controlling for trait avoidance and anxiety, age, gender, ingroup identification, and political orientation. After including the control variables, results revealed that, compared to the control condition, the interventions failed to exert a significant effect on negative emotions towards terrorists, towards Muslims, and towards one's own government, dehumanization of terrorists, competitive victimhood, ingroup government responsibility, outgroup (non-ISIS Muslim) responsibility, and future forgiveness of ISIS (all $F_{\mathrm{s}}<1.65$, all $p \mathrm{~s}>.18$; all $\eta^{2} \mathrm{~s}<.018$ ). The same pattern of findings also held up when no control variables were included (all $F \mathrm{~s}<1.34$, all $p \mathrm{~s}>.26$; all $\eta^{2} \mathrm{~s}$ $<.014)$ 
As a minor variation from the results of Study 1, a significant effect of the intervention factor was found for punitiveness $\left(F=3.46, p=.017 ; \eta^{2}=.037\right)$, and a borderline significant intervention effect was found for reconciliation towards non-ISIS Muslims $(F=2.58, p$ $\left.=.054 ; \eta^{2}=.028\right)$. Pairwise comparisons indicated that punitiveness towards ISIS was lower in the secure attachment (vs. control) condition ( $\Delta$ secure attachment-control $=-0.45 ; p=.030)$ and dissonance (vs. control) condition ( $\Delta$ dissonance-control $=-0.44 ; p=.040)$. Similarly, reconciliation towards Muslims was higher in the secure attachment (vs. control) condition $(\Delta$ secure attachment-control $=0.43 ; p=.041)$. Crucially, however, analyses without control variables rendered this significant intervention effect on punitiveness to barely reach significance levels $\left(F=2.27, p=.081 ; \eta^{2}=.024\right)$. Furthermore, pairwise comparisons without control variables on punitiveness produced a borderline significant difference between the secure attachment and control condition $(\Delta$ secure attachment-control $=-0.42 ; p=.082)$, and a non-significant difference between the dissonance and control condition ( $\Delta$ dissonance-control $=-0.33 ; p>.250)$.

\section{Bayesian Analyses}

To directly test the null hypothesis model (Gallistel, 2009), we calculated Bayes factors for the main effect of our experimental manipulation on all ten outcomes (see Table 2). For negative emotions towards terrorists, negative emotions towards one's own government, and ingroup government responsibility, and future forgiveness, these indices yielded very strong $(<0.033)$ support in favor of the null model. For negative emotions towards Muslims, competitive victimhood, and outgroup responsibility, there was strong $(<.10)$ evidence for the null model. For dehumanization, reconciliation, and punitiveness, we found moderate $(<0.333)$ support for the null model. For instance, the Bayes factors for the experimental manipulation having an impact on emotions towards terrorists, on emotions towards Muslims, and on punitiveness suggest that, respectively, it is about 45, 18, and 3.4 
times more likely that the manipulation did not have an impact than that it did (Table 2).

Although somewhat smaller in size than in Study 1, these Bayesian analyses again corroborate the frequentist analyses, indicating that the intervention effects are either negligible or very small.

\section{Table 2.}

Bayes factors for the manipulation effect on each outcome in Study 2, comparing the probability of the $H^{a}$ model (i.e., "there is an effect") being true as opposed to the $H^{0}$ model (i.e., "there is no effect") being true. Smaller Bayes factors indicate that the data is in support of the Ho model.

\begin{tabular}{lc}
\hline Dependent Variable & Manipulation \\
\hline Negative emotions towards terrorists & 0.022 \\
Negative emotions towards Muslims & 0.057 \\
Negative emotions towards own government & 0.024 \\
Dehumanization of terrorists & 0.314 \\
Competitive victimhood & 0.072 \\
Ingroup government responsibility & 0.026 \\
Outgroup (non-ISIS Muslim) responsibility & 0.091 \\
Reconciliation towards non-ISIS Muslims & 0.302 \\
Future forgiveness of ISIS & 0.019 \\
Punitiveness (torture justification) & 0.297 \\
\hline
\end{tabular}

\section{General Discussion}

Two studies aimed to compare the relative effectiveness of three established intergroup bias-reduction interventions among groups with varying degrees of proximity to actual real-life terror attacks. These interventions are the products of theories that have coevolved independently. Therefore, their relative effectiveness has not been tested, leading to disparate strands of literature. The current research investigated the comparative effectiveness of these interventions concurrently. It also aimed to move these interventions to real-life 
settings from laboratory contexts that often employ minimal group paradigm with little history of intergroup tension, hostility, and terror (Hebl \& Dovidio, 2005).

Unlike past research, which tended to employ small to modest sample sizes ( $N \mathrm{~s}$ ranging from 21 to 251; with the exception of Saleem et al.'s 2015 samples, which comprised between 278 to 307 participants), the present work used a high powered, heterogeneous adult sample in Study $1(N=1676)$ and a moderately powered, homogenous student sample in Study $2(N=285)$. Our data were collected from participants on online platforms (Study 1$)$ and students in the lab (Study 2). If heterogeneity suppressed the effects in Study 1 due to the regional and political diversity of the sample, such diversity was absent in the sample of Study 2. Furthermore, to rule out the possibility that the immediacy and magnitude of the terror attacks may have suppressed the effects of the three interventions in Study 1 due to “freezing”, Study 2 was conducted two and half years after Study 1. Unexpectedly, the results from frequentist analyses show that these interventions (vs. control) were ineffective. Bayesian analyses further corroborated these findings by revealing that the data showed very strong to extreme (Study 1) and moderate to very strong (Study 2) support for the null hypothesis model.

The current research reveals the cold facts that none of the established interventions was sufficiently potent to ameliorate intergroup negativity post terror attacks. These results were replicated across countries with varying proximity to the attacks, and among both online and laboratory contexts. Setting the studies against the backdrop of two major terror attacks may have provided a challenging test for these interventions because the effects found in previous studies were small (e.g., $\eta^{2}$ s $<.119$; Mikulincer \& Shaver, 2001). Such effects might be too small to be observed in the face of terror threat even though the current studies are sufficiently powered with close to 2,000 online and offline participants across four countries and two continents. 
An important limitation of the current work is that the interventions were used one time only, and the order in which the outcomes were presented was not counterbalanced. Although these methods are consistent with the paradigm used in the literature (e.g., ČehajićClancy et al., 2011; Exline et al., 2008; Saleem, et al., 2015), it is possible that, for example, a one-time intervention is not sufficient given the devastating magnitude and nature of terror attacks. Future research should explore the effectiveness of more prolonged and repeated exposures to these interventions. Such "wise" interventions (Walton, 2014) should target recursive processes to cause lasting changes. They should also be context-dependent, so we can clearly delineate what type of intervention works in which situation. Thirdly, a wise intervention needs to be psychologically precise. To illustrate, a lesson from the present research might be that the interventions tested here might not have sufficiently and specifically addressed the specific nature of threats, such as threats to safety and security, emanating from terrorist acts (Neuberg \& Schaller, 2016). While past research has shown that our selected interventions may be quite versatile by exerting effects on a range of outcome variables across lab-based or post-conflict settings (e.g., Čehajić-Clancy et al., 2011; Exline et al., 2008; Saleem et al., 2015), such versatility may have dampened their effectiveness in contexts of terror attacks, because the interventions were not sufficiently specific to address our participants' threatened needs for safety and security.

Another important lesson of the present research is for social psychologists to reconsider the balance between internal and ecological validity in theory and empirical development. The historic trend in setting "neat" stories and "conclusive" findings as the implicit minimum criteria for publication seems to have pushed the balance more towards prioritizing internal validity over ecological validity (Hebl \& Dovidio, 2005). This trend can be detrimental in many respects. It can strip research from its societal relevance leading to a disconnect between research and practice (Giner-Sorolla, 2019; Paluck \& Green, 2009). As 
such, the present work highlights the indispensability of testing the ecological validity of social psychological theories. In particular, as intergroup conflicts are intensifying across the world, within and between national boundaries, a better understanding the depths of their impacts - and how to ameliorate them - are ever-more important. 


\section{References}

Adams, G., Tormala, T. T., \& O'Brien, L. T. (2006). The effect of self-affirmation on perception of racism. Journal of Experimental Social Psychology, 42, 616-626.

Baumeister, R. F. (1997). Evil: Inside human cruelty and violence. New York: WH Freeman. Bowlby, J. (1969). Attachment and loss (1st ed.). New York, NY: Basic Books.

Buhrmester, M., Kwang, T., \& Gosling, S. D. (2011). Amazon's Mechanical Turk: A new source of inexpensive, yet high-quality, data?. Perspectives on Psychological Science, 6(1), 3-5.

Carnelley, K. B., \& Rowe, A. C. (2010). Priming a sense of security: What goes through people's minds?. Journal of Social and Personal Relationships, 27(2), 253-261.

Čehajić-Clancy, S., Effron, D. A., Halperin, E., Liberman, V., \& Ross, L. D. (2011). Affirmation, acknowledgment of in-group responsibility, group-based guilt, and support for reparative measures. Journal of Personality and Social Psychology, 101, 256-271.

Chen, B., Van Assche, J., Vansteenkiste, M., Soenens, B., \& Beyers, W. (2015). Does psychological need satisfaction matter when environmental or financial safety are at risk?. Journal of Happiness Studies, 16(3), 745-766.

Doosje, B., Branscombe, N. R., Spears, R., \& Manstead, A. S. (1998). Guilty by association: When one's group has a negative history. Journal of Personality and Social Psychology, 75(4), 872-886.

Festinger, L. (1962). A Theory of Cognitive Dissonance (Vol. 2). Stanford University Press. Festinger, L., Cartwright, D., Barber, K., Fleischl, J., Gottsdanker, J., Keysen, A., \& Leavitt, G. (1948). A study of a rumor: its origin and spread. Human Relations, 1, 464-486.

Echebarria-Echabe, A., Fernàndez-Guede, E. (2006). Effects of Terrorism on Attitudes and Ideological Orientation. European Journal of Social Psychology, 36, 259-265. 
Exline, J. J., Baumeister, R. F., Zell, A. L., Kraft, A. J., \& Witvliet, C. V. (2008). Not so innocent: Does seeing one's own capability for wrongdoing predict forgiveness?. Journal of Personality and Social Psychology, 94, 495-515.

Fabrigar, L. R., \& Wegener, D. T. (2016). Conceptualizing and evaluating the replication of research results. Journal of Experimental Social Psychology, 66, 68-80.

Fein, S., \& Spencer, S. J. (1997). Prejudice as self-image maintenance: Affirming the self through derogating others. Journal of Personality and Social Psychology, 73(1), 3144.

Gallistel, C. R. (2009). The importance of proving the null. Psychological Review, 116(2), 439-453.

Gillath, O., Sesko, A. K., Shaver, P. R., \& Chun, D. S. (2010). Attachment, authenticity, and honesty: dispositional and experimentally induced security can reduce self-and otherdeception. Journal of Personality and Social Psychology, 98(5), 841-855.

Giner-Sorolla, R. (2019). From crisis of evidence to a "crisis" of relevance? Incentive-based answers for social psychology's perennial relevance worries. European Review Of Social Psychology, 30, 1-38.

Goodman, J. K., Cryder, C. E., \& Cheema, A. (2013). Data collection in a flat world: The strengths and weaknesses of Mechanical Turk samples. Journal of Behavioral Decision Making, 26(3), 213-224.

Hebl, M. R., \& Dovidio, J. F. (2005). Promoting the "social" in the examination of social stigmas. Personality and Social Psychology Review, 9, 156-182.

Kaiser, C. R., Vick, S. B., \& Major, B. (2004). A prospective investigation of the relationship between just-world beliefs and the desire for revenge after September 11, 2001. Psychological Science, 15, 503-506. 
Kruglanski, A. W., \& Fishman, S. (2009). Psychological factors in terrorism and counterterrorism: Individual, group, and organizational levels of analysis. Social Issues and Policy Review, 3, 1-44.

Kteily, N., Bruneau, E., Waytz, A., \& Cotterill, S. (2015). “The ascent of man”: A theoretical and empirical case for blatant dehumanization. Journal of Personality and Social Psychology, 109, 901-931.

Lehmiller, J. J., Law, A. T., \& Tormala, T. T. (2010). The effect of self-affirmation on sexual prejudice. Journal of Experimental Social Psychology, 46(2), 276-285.

Lickel, B., Miller, N., Stenstrom, D. M., Denson, T. F., \& Schmader, T. (2006). Vicarious retribution: The role of collective blame in intergroup aggression. Personality and Social Psychology Review, 10, 372-390.

McGregor, I., Haji, R., \& Kang, S. J. (2008). Can ingroup affirmation relieve outgroup derogation?. Journal of Experimental Social Psychology, 44, 1395-1401.

Mikulincer, M., \& Shaver, P. R. (2001). Attachment theory and intergroup bias: evidence that priming the secure base schema attenuates negative reactions to out-groups. Journal of Personality and Social Psychology, 81, 97-115.

Mikulincer, M., Shaver, P. R., Gillath, O., \& Nitzberg, R. A. (2005). Attachment, caregiving, and altruism: boosting attachment security increases compassion and helping. Journal of Personality and Social Psychology, 89(5), 817-839.

Morey, R. D., \& Rouder, J. N. (2015). BayesFactor: Computation of Bayes factors for common designs [Computer software manual] (R package version 0.9.12-2). Retrieved from https://cran.r-project.org/package=BayesFactor.

Neuberg, S. L., \& Schaller, M. (2016). An evolutionary threat-management approach to prejudices. Current Opinion in Psychology, 7, 1-5. 
Panagopoulos, C. (2006). The Poll-Trends. Arab and Muslim Americans and Islam in the Aftermath of 9/11. Public Opinion Quarterly, 70, 604-624.

Paluck, E. L., \& Green, D. P. (2009). Prejudice reduction: What works? A review and assessment of research and practice. Annual Review of Psychology, 60, 339-367.

Pezzo, M. V., \& Beckstead, J. W. (2006). A multilevel analysis of rumor transmission: Effects of anxiety and belief in two field experiments. Basic and Applied Social Psychology, 28, 91-100.

Prasad, J. (1935). The psychology of rumour: A study relating to the great Indian earthquake of 1934. British Journal of Psychology, 26, 1-15.

Pratt, D. (2015). Reactive Co-Radicalization: Religious Extremism as Mutual Discontent. Journal for the Academic Study of Religion, 28(1).

Saleem, M., Prot, S., Cikara, M., Lam, B. C., Anderson, C. A., \& Jelic, M. (2015). Cutting Gordian knots: Reducing prejudice through attachment security. Personality and Social Psychology Bulletin, 41, 1560-1574.

Schauer, M., \& Elbert, T. (2010). Dissociation following traumatic stress: Etiology and Treatment. Zeitschrift für Psychologie/Journal of Psychology, 218(2), 109-127.

Shnabel, N., Halabi, S., \& Noor, M. (2013). Overcoming competitive victimhood and facilitating forgiveness through re-categorization into a common victim or perpetrator identity. Journal of Experimental Social Psychology, 49, 867-877.

Schmidt, N. B., Richey, J. A., Zvolensky, M. J., \& Maner, J. K. (2008). Exploring human freeze responses to a threat stressor. Journal of Behavior Therapy and Experimental Psychiatry, 39(3), 292-304.

Sherman, D. K., \& Cohen, G. L. (2006). The psychology of self-defense: Self-affirmation theory. Advances in Experimental Social Psychology, 38, 183-242. 
Shrout, P. E., \& Rodgers, J. L. (2018). Psychology, science, and knowledge construction: Broadening perspectives from the replication crisis. Annual review of psychology, 69, 487-510.

Stone, J., Whitehead, J., Schmader, T., \& Focella, E. (2011). Thanks for asking: Selfaffirming questions reduce backlash when stigmatized targets confront prejudice. Journal of Experimental Social Psychology, 47, 589-598.

The Guardian (2017). London attack: 'Aggressive' and 'strange' suspect vowed to 'do some damage'. Retrieved from https://www.theguardian.com/uk-news/2017/jun/19/severalcasualties-reported-after-van-hits-pedestrians-in-north-london.

Van Assche, J., Van Hiel, A., Dhont, K., \& Roets, A. (2019). Broadening the individual differences lens on party support and voting behavior: Cynicism and prejudice as relevant attitudes referring to modern-day political alignments. European Journal of Social Psychology, 49(1), 190-199.

Van de Vyver, J., Houston, D. M., Abrams, D., \& Vasiljevic, M. (2016). Boosting Belligerence How the July 7, 2005, London Bombings Affected Liberals' Moral Foundations and Prejudice. Psychological Science, 27, 169-177.

Walton, G. M. (2014). The new science of wise psychological interventions. Current Directions in Psychological Science, 23(1), 73-82. 